\title{
A Measurement Scale for Indecisiveness and its Relationship to Career Indecision and Other Types of Indecision
}

\author{
Veerle Germeijs and Paul De Boeck \\ Catholic University Leuven, Belgium
}

Keywords: Indecisiveness scale, career indecision, indecisiveness

\begin{abstract}
Summary: A scale for indecisiveness was constructed and then used to investigate distinctive features of indecisiveness. In the literature on decision making, the distinction between indecision and indecisiveness is an important issue, but evidence showing that these two constructs are different is lacking. We found clear evidence for such a distinction, from a joint exploratory factor analysis of the indecisiveness scale and a career indecision scale, and from the differential relation of both with self-esteem as a third variable. Furthermore, with confirmatory factor analysis, we found that the correlations between items on career indecision cannot be explained only by indecisiveness, and that also a factor specific to the situation of career decision is needed. These results corroborate the distinction between career indecision and indecisiveness. Although it must be differentiated from specific types of indecision, such as career indecision, indecisiveness turned out to be a correlate of the specific indecisions - one that can explain the intercorrelations between different kinds of more specific indecision.
\end{abstract}

Deciding and judging are some of the most fundamental activities in our lives. We constantly have to make decisions. Not all decisions are of major importance, but some are. Sometimes, decisions can be easily, but we all have experienced situations where deciding is difficult and stressful. One of the important areas of decision making concerns one's career (Osipow, 1999; Slaney, 1988). Career counselors try to facilitate the career decision-making process of high school students, college students, and adults by supporting them in the difficulties they encounter during their educational and career decisions. Therefore, identifying the difficulties that discourage these students from making a decision has become an important research topic in career psychology.

Early research on career decision making indicated the complexity of career indecision and suggested that multiple forms of indecision may exist (Crites, 1969; Tyler, 1969). More recent research has focused on the definition and determination of several types and catego- ries of career indecision (Wanberg \& Muchinsky, 1992). A topic considered in most typologies of career indecision is that of the differentiation between indecision and indecisiveness. Gati, Krausz, and Osipow (1996) and Gati, Osipow, Krausz, and Saka (2000), for example, developed and tested a taxonomy of career decisionmaking difficulties, thereby reorganizing a number of previously studied difficulties into one theoretical framework. They found that the various difficulties associated with career indecision could be classified into 10 meaningful categories, one of which is described as "general indecisiveness for all types of decision making."

Concerning the distinction between indecision and indecisiveness, indecision with regard to a specific domain or situation, such as career indecision, doesn't necessarily imply that one has problems with making decisions in other situations. In contrast with indecision, indecisiveness generalizes across decision situations. Based on the definitions of indecisiveness in the literature, Crites 
(1969) describes indecisive persons as "individuals who seem to have difficulty in making all sorts of life decisions, whether they are of great or little significance" (pp. 305-306). To distinguish between indecision and indecisiveness, Crites (1969) defined an indecisive person as "one who cannot make a vocational choice even after all the conditions for doing so, such as choice supply, incentive to make a choice, and the freedom to choose, are provided" (p. 306). The literature discusses the relationships between indecisiveness and personality characteristics. For example, Salomone (1982) observed clients in a rehabilitation practice who could not make decisions even after long, step-by-step decision-making series of interviews. According to Salomone (1982), who called these clients indecisive, such persons had typical personality characteristics like a low self-confidence and low self-esteem, an unclear sense of separate identity, helplessness, high levels of ambivalence and frustration, externalized locus of control, and a tendency to blame others for their situation.

Slaney (1988) criticizes the lack of attention paid to the distinction between career indecision, which is a kind of situation specific indecision, and indecisiveness. Although the distinction between career indecision and indecisiveness is recognized as useful, Slaney (1988) commented that "very little progress has been made thus far in demonstrating that the two constructs are valid and discriminable" (pp. 44-45).

The distinction between career indecision and indecisiveness can be important for career counselors (Osipow, 1999; Slaney, 1988). Career indecision could be remedied by obtaining relevant career and personal information or through standard career interventions. Indecisiveness would need a more intensive treatment with attention for personality antecedents of the decision problem. Therefore, it is not surprising that in a lot of instruments for career indecision a indecisiveness subscale is included. Instruments like the Career Factors Inventory (Chartrand, Robbins, Morril, \& Boggs, 1990) and the Career Decision Profile (Jones, 1989), for example, contain such a subscale. Other researchers like Cooper, Fuqua, and Hartman (1984) and Frost and Shows (1993) set up a separate scale for indecisiveness.

The way indecisiveness is measured seems to differ greatly across instruments. Although they agree that indecisiveness has to do with difficulties in dealing with decisions concerning different life issues, the way these difficulties are phrased into items differs from scale to scale and from item to item even within the same scale. We highlight two differences here with consequences for the purity of the scale. An important difference is that some items refer to aspects of the decision-making process (latency, postponement, regret, etc.), whereas others do not, but rather refer to variables that may be consid- ered as causal factors or correlates, for example, self-esteem and feelings of helplessness. Items like "While making most decisions I am slow/quick" (Career Factors Inventory, Chartrand et al., 1990) and "I try to put off making decisions" (Indecisiveness scale, Frost \& Shows, 1993) refer to the decisional process itself, whereas items like "I seem not to feel good about myself much of time," "I often feel helpless in dealing with unpleasant situations" (Indecisiveness scale, Cooper et al., 1984), and "For me decision making seems frustrating/fulfilling" (Career Factors Inventory, Chartrand et al., 1990) refer to feelings that may be correlates or causal factors of indecisiveness. Although research shows that there is a relationship between decision problems and personality characteristics, like low self-esteem (Kishor, 1981; Salomone, 1982; Serling \& Betz, 1990), when items referring to such characteristics are included, the resulting measure of indecisiveness is confounded, so that it is no longer appropriate for studying the relation between indecisiveness and these other variables.

Another important difference is between items pointing to specific situations and items of a more general nature. For example, in the indecisiveness scale of Frost and Shows (1993), some items refer to specific situations like "I have a hard time planning my free time" or "When ordering from a menu, I usually find it difficult to decide what to get," whereas others are more general like "I find it easy to make decisions." It can be expected that people who are indecisive in general display undecided behavior at many specific decision points during life, so that the items of general indecisiveness and situational indecision correlate. However, a person can also be undecided in a number of specific situations without being generally indecisive. Questions concerning decision problems in specific situations can be used to validate an indecisiveness scale, but they should not be included in the scale about general indecisiveness itself. If they were included nevertheless, another type of confounding results, one that prevents one from investigating the contribution of indecisiveness to indecision.

The first purpose of the present study is to construct an unconfounded measurement scale for indecisiveness, taking into consideration the remarks above. This means avoiding confounding with related variables and with indecision. The development of the items was based on existing scales of indecisiveness (Chartrand et al., 1990; Cooper et al., 1984; Frost \& Shows, 1993; Jones, 1989) and on literature describing indecisiveness (Crites, 1969; Dosnon, Wach, Blanchard \& Lallemand, 1997; Gati et al., 1996; Osipow, 1999; Wanberg \& Muchinsky, 1992). The following criteria for determining the content of the items were extracted:

1) Descriptors for the difficulty in making decisions are: 
deciding takes a long time; a tendency to delay making decisions; a tendency to avoid making decisions; leaving decisions to someone else; instability of a decision; worrying about decisions that are made; regretting decisions that are made.

2) Indecisiveness does not refer to any specific kind of decision, but to all kinds of decisions instead.

These are all aspects of decision making itself, which we consider essential for the measurement of indecisiveness (Frost \& Shows, 1993).

A second purpose of this study is to confront the critique of Slaney (1988) and Osipow (1999) about the lack of empirical support in demonstrating that career indecision and indecisiveness are two separate constructs. To investigate the differentiation between career indecision and indecisiveness, we constructed a scale for career indecision but otherwise parallel to the indecisiveness scale. We specified career indecision as decision problems of high school students concerning further studies. Two hypotheses are formulated regarding indecisiveness and career indecision: First, it is hypothesized that the two scales each correspond to a separate factor when the items of the two scales are subjected to a factor analysis: a career indecision factor and an indecisiveness factor. Second, we hypothesize that the two scales differ in the correlations they show with self-esteem. We know from other studies that decision problems go hand in hand with low self-esteem, from which we conclude that indecisiveness is correlated more negatively with self-esteem than indecision is correlated with self-esteem. A specific kind of indecision such as career indecision can have all kinds of specific causes other than low self-esteem. If indecisiveness is a more complex problem rooted in the personality of the decision-maker, then one may indeed expect a larger association of self-esteem with indecisiveness than with an indecision variable.

The third purpose of this study was to investigate the contribution of indecisiveness to situation-specific indecision. From the characteristics of indecisiveness, a significant effect of indecisiveness is expected on problems with decision making in different situations. We further expect that, except for indecisiveness, all other factors affecting indecision would be of a kind that is specifically associated with the topic of indecision. Therefore, our third hypothesis is that the effect of indecisiveness on career indecision and other specific types of indecision is significant, and that a path model without further common effects on types of indecision can explain the correlations between these types. To test this third hypothesis between the different types of indecision, students are asked to indicate decision problems for different types of daily decisions.

To find further evidence for the differentiation be- tween career indecision and indecisiveness, the path model constructed for the third hypothesis was compared with an alternative model in which also the correlations between different career indecision variables can be explained by indecisiveness, so that no separate career indecision concept is needed. It is hypothesized that such a model will not fit, and that career indecision is needed indeed as a separate notion behind the different career indecision variables.

\section{Materials and Methods}

\section{Procedure and Subjects}

Students of the sixth (and last) year in two high schools in the Dutch-speaking part of Belgium received a questionnaire in May. Only students likely to continue to study after high school could participate in the research. For others, the issue of career indecision specified as concerning further studies was irrelevant. Participation in the study was anonymous. Of the 292 students who received the questionnaire 184 returned them. For the analyses, the data of 10 students were not included because they were incomplete. Out of the 174 remaining students, 30 students had already answered the same questionnaires for a pilot study in January.

The students first answered the questions on indecisiveness, after which the questionnaire about study choice followed. There is no good solution to the order problem. Counterbalancing is not a good solution, since the first measure may affect the second in both order conditions, counteracting a possible genuine differentiation between the two. The purpose of the present study is to construct a measurement scale for indecisiveness. Primarily, we wanted to avoid answers on the indecisiveness scale being influenced by answers on the career indecision scale. It can be expected that when presenting the scales in the reversed order, the students would not bring enough other decision situations into account when answering the indecisiveness items.

After answering the career decision items, the students answered questions about several kinds of daily decisions. The self-esteem scale was presented at the end.

\section{Questionnaires}

The students received four different questionnaires: one on indecisiveness, another on indecision regarding the choice of further studies, one about self-esteem, and a very brief questionnaire about six different kinds of daily decisions. 
Indecisiveness. To measure indecisiveness, a 22-item Likert-type questionnaire was constructed on the basis indicated earlier. Eleven features have been discerned: difficulty, don't know how, feeling uncertain, takes a long time, delaying, avoidance, leaving to others, reconsideration, worrying, regretting, and calling oneself indecisive (see criterion 1 mentioned above). For each feature, we tried to find a positively and negatively formulated item, to counteract response tendencies, so that the total number of items was 22 . The students were told that the questionnaire concerned decision making in general, in all kinds of situations. Each item was formulated as a statement for which the subjects had to indicate the extent of agreement on a 7-point scale going from (0) strongly disagree to (6) strongly agree. The 22 items are listed in Table 1 (in English). In the questionnaire the items were actually randomly ordered. In this study, the internal consistency (Cronbach's $\alpha$ ) for the 22-item scale was .91. The Cronbach's $\alpha$ coefficients for the positive and negative items of the indecisiveness scale were .83 and .86 respectively.

Career indecision. The items of this scale were formulated parallel to those of the indecisiveness scale, but now the students were asked to answer the questions with respect to their decision on further studies. Nevertheless, for 7 items the formulation had to be adapted (item 5: I would characterize myself as an indecisive person regarding this situation; item 14: I don't avoid making this decision; item 17: I don't often change my opinion in this decision; item 19: I don't worry about this decision; item 20: I can't get this decision out of my mind; item 21: I often believe I have made/will make the wrong decision; item 22: I am sure I will not regret my decision). For the other items the words decisions and a decision in the indecisiveness scale were simply replaced by the word this decision. In the instructions, it was mentioned that the questions were the same as in the former part, but that they had to answer them now with the specific decision on choosing further studies in mind. The internal consistency (Cronbach's $\alpha$ ) for the 22-item scale was .96 in this study. The Cronbach's $\alpha$ coefficients for the positive and negative items of the career indecision scale were .90 and .94 , respectively.

Finally, the students are asked separately how far they have made progress with their decision. They were given four response categories: (1) I have already decided what to study next year; (2) I know what kind of studies I want, but I have not made a definitive choice yet; (3) I am still considering different options; (4) I really don't have any idea about what kind of study I want to do next year.

Self-esteem. The self-esteem scale we used was a global self-esteem scale constructed by Mertens (1997). It con-
Table 1. Items for the indecisiveness scale.

1. I find it easy to make decisions.

2. It is hard for me to come to a decision.

3. I don't know how to make decisions.

4. I know which steps to take when making a decision.

5. I would characterize myself as an indecisive person.

6. I don't hesitate much when I have to make a decision.

7. While making a decision, I feel certain.

8. While making a decision, I feel uncertain.

9. It takes a long time to weigh the pros and cons before making a decision.

10. I make decisions quickly.

11. I delay deciding.

12. I don't postpone making decisions to a later date.

13. I try to avoid making a decision.

14. I don't avoid situations where decisions have to be made.

15. I tend to leave decisions to someone else.

16. I cut the knot myself in a decision instead of leaving the decision to others.

17. Once I have taken a decision, I stick to that decision.

18. I often reconsider my decision.

19. Once I have made a decision, I stop worrying about it.

20. After making a decision, I can't get it out of my mind.

21. After I have decided something, I believe I took the wrong decision.

22. After making a decision, I don't regret the decision.

sists of ten items of the Likert-type, the responses to which had to be made on a 4-point scale from (1) little applicable to me to (4) for the most part applicable to me. Examples of the ten items are: "I am worthwhile," "I am proud of myself," and "I would like to be different."

This scale is part of a multidimensional self-concept scale in which also physical self-concept, social selfconcept, and academic self-concept are measured. The reliability of the global self-esteem scale with 10 items was quite high $(\alpha=.87)$. This global self-esteem scale shows high correlations with the Global Self-Worth subscale of the Self-Perception Profile for Adolescents (Harter, 1988) and the General Self subscale of the Self-Description Questionnaire II (Marsh, 1992): .67, and .71, respectively.

Daily decisions. The students were asked to indicate on a 7-point scale from (0) strongly disagree to (6) strongly agree, to which extent they have problems with decisions in different life domains. The six items are: "It's difficult for me to decide in the morning which clothes to wear." - "When ordering from a menu in a restaurant, I find it easy to decide what to get." - "It's easy for me to decide what to do in my free time." - "When I want to start studying my lessons, I find it difficult to choose the course that I want to study." - "When I go to the cinema, I find it easy to make a choice for one out of several movies." - "I have a hard time choosing a present for someone." 


\section{Data Analysis}

For the data analysis, responses to negatively formulated items were reversed so that for all items on decision making 0 represents problems in decision making and 6 means there are no problems. Also, for the self-esteem scale responses were reversed so that for all items of this scale 0 represents a low self-esteem and 4 represents a high self-esteem.

Indecisiveness scale. In order to check whether the items of the indecisiveness scale could be seen as measurements of the same underlying construct of indecisiveness, a principal components analysis was done on the 22 items about indecisiveness. For 30 students who participated also in the pilot study, the correlation between the score on the indecisiveness scale of January and of May was calculated, in order to have an indication of the test-retest reliability. Also for the career indecision scale, this correlation was calculated.

Differentiation between indecisiveness and career indecision. Concerning the differentiation between career indecision and indecisiveness, a principal components analysis was done on the total set of items from the indecisiveness scale and from the career indecision scale. Second, the correlation of the score on the self-esteem scale was calculated with both the score on the career indecision scale and the score on the indecisiveness scale. To test for the difference between the two correlations, a $t$-test was conducted.

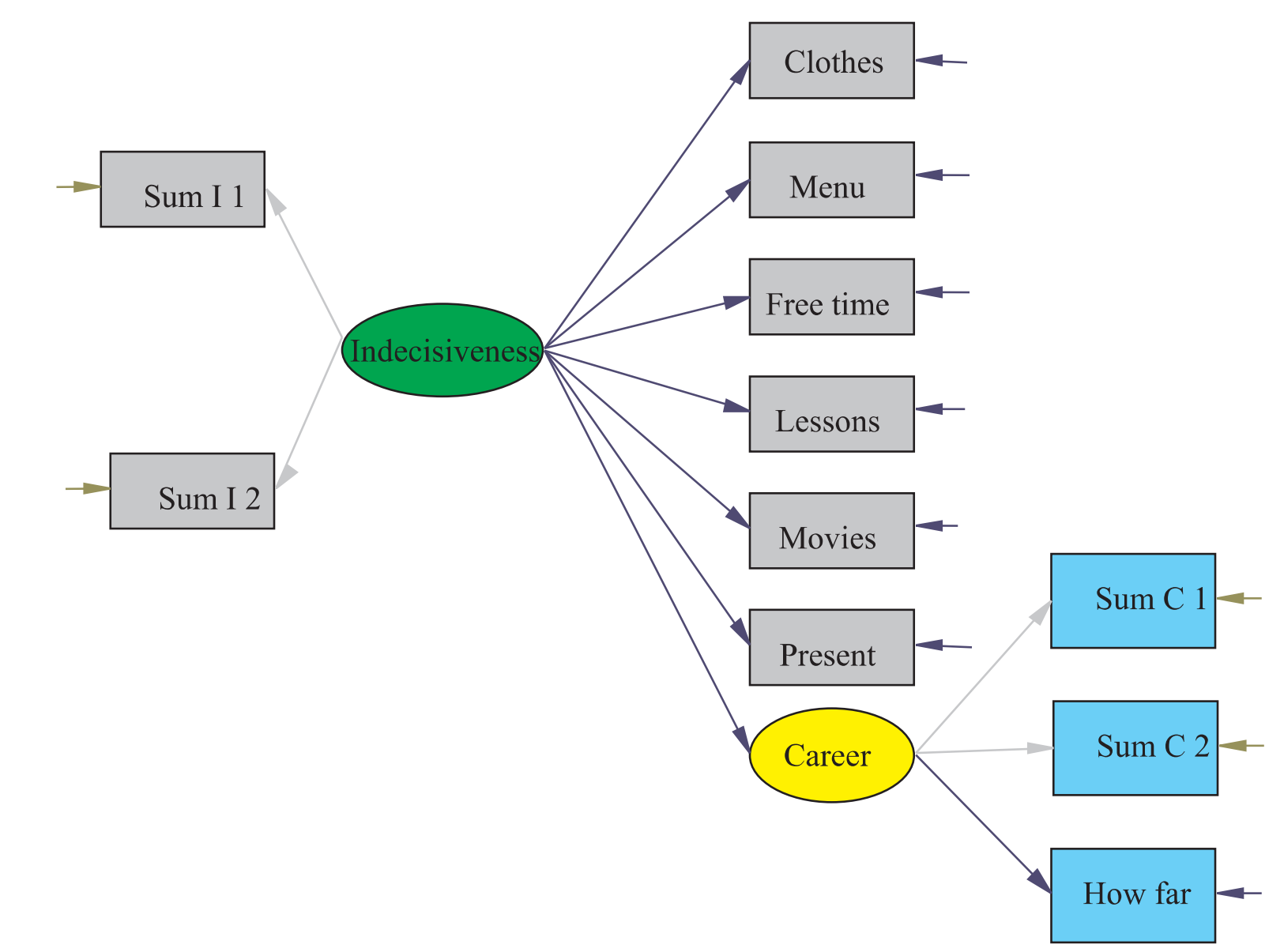

Figure 1. Structural model for the contribution of indecisiveness to indecision.

Sum I 1 = sum score of the first eleven items of the indecisiveness scale; Sum I 2 = sum score of the last eleven items of the indecisiveness scale; Indecisiveness = latent variable "indecisiveness"; Clothes = item score of "It is difficult for me to decide in the morning which clothes to wear."; Menu = item score of "When ordering from a menu in a restaurant, I find it easy to decide what to get."; Free time = item score of "It's easy for me to decide what to do in my free time."; Lessons = item score of "When I want to start studying my lessons, I find it difficult to choose the course that I want to study."; Movies = item score of "When I go to the cinema, I find it easy to make a choice for one out of several movies."; Present = item score of "I have a hard time choosing a present for someone."; Sum C 1 = sum score of the first eleven items of the career indecision scale; Sum C $2=$ sum score of the last eleven items of the career indecision scale; How far = item score of "How far have you made progress with your decision?"; Career = latent variable "career indecision." 
Contribution of indecisiveness to situational indecision. To investigate the contribution of indecisiveness to situational indecision, a confirmatory factor analysis was performed for indecisiveness, career indecision, and indecision in daily decision situations. In the model (see Figure 1), a latent indecisiveness variable is identified by two indicator variables, the sum score of the first eleven items and the sum score of the last eleven items. Latent indecisiveness is supposed to have an effect on all specific types of indecision, career indecision included. However, the latter is defined to be a latent variable with three indicators: the sum of the first eleven items, the sum of the last eleven items, and the separate question on how far they had made progress with their career decision. For the split-half indicators, equality restrictions were used for the factor loadings and the error variances. Actually, the factor loadings were set equal to one in order to be able to test the measurement models.

The model is estimated with LISREL 8 (Jöreskog, Sörbom, du Toit, \& du Toit, 1999) using the covariance matrix and maximum likelihood estimations. Based on Byrne (1998), we would like to use, beside the $p$-value of the $\chi^{2}$ statistic, also the root mean square error of approximation (RMSEA) and the test of close fit as measures of fit, because the $\chi^{2}$ statistic is very sensitive to sample size, and because the assumption of a perfect fit in the population is made when using this statistic. Browne and Cudeck (1993) suggested that a RMSEA smaller than .05 indicates a good fit, and that values as high as .08 represent reasonable errors of approximation in the population. Jöreskog and Sörbom (1996) suggested that the $p$-value of the test of close fit should be larger than .50 .

Concerning the differentiation between career indecision and indecisiveness, a second model was formulated and tested with confirmatory factor analysis. In this model career indecision was omitted as a latent variable, and a direct effect of indecisiveness was assumed to explain the correlations between the career indecision variables. By comparing the fit of both models, it becomes clear whether or not career indecision is also needed as a latent variable differentiated from (although affected by) indecisiveness. If the correlations between the three manifest career indecision variables from Figure 1 can be explained by the latent indecisiveness variable, then there is no reason for a separate indecision concept.

In this study the total sample size is too small to test for invariance of the structural equation models across split-half samples. In order to investigate the stability of the structural equation models under cross-validation and to avoid splitting the available data - the expected cross validation index (ECVI) can be used (Browne \& Cudeck, 1989; Browne, 2000). The ECVI measures the discrepancy between the fitted covariance matrix in the analyzed sample and the expected covariance matrix that would be obtained in another sample of equivalent size. Application of the ECVI assumes a comparison of models, whereby the model having the smallest ECVI exhibits the greatest potential for replication (Byrne, 1998). The ECVI of the two alternative models are compared, together with the ECVI of the saturated model and the independence model. In order to find further evidence for the cross-validation of the differentiation between career indecision and indecisiveness, the sample was split randomly into two groups of equal size. For both groups, the partial correlation coefficients between the three manifest career indecision variables from Figure 1 are calculated controlling for indecisiveness.

\section{Results}

\section{Indecisiveness Scale}

From the principal components analysis of the 22 items of the indecisiveness scale, five factors with an eigenvalue larger than 1.00 were obtained. The eigenvalues of these factors are 8.02, 1.72, 1.48, 1.13, and 1.06, the first eigenvalue being almost five times as large as the second. Also, using the scree test, a one-factor solution should be preferred. This factor accounts for $36.45 \%$ of the variance in the items. The loadings of the items for the onefactor solution are shown in Table 2. Of the 22 items, only one has a loading lower than .40 .

The test scores for 30 students, on the same scale were obtained in a pilot study 4 months before this study. The test-retest reliability turned out to be $.67(p<.01)$. The test-retest reliability of the career indecision scale was $.76(p<.01)$. These results indicate that indecisiveness as well as career indecision are quite stable over time.

\section{Differentiation Between Indecisiveness and Career Indecision}

The first hypothesis concerns the differentiation between career indecision and indecisiveness. Nine factors with eigenvalues larger than 1.00 were obtained from a principal components analysis on the 44 items of the indecisiveness scale and the career indecision scale. These eigenvalues are 14.21, 5.67, 2.29, 1.67, 1.52, 1.30, 1.21, 1.17 , and 1.02. The first two are much larger than the others, suggesting there are mainly two factors. These two factors explained $45.18 \%$ of the variance in the data.

The varimax rotation for the two-factor solution is shown in Table 3. For each item, the highest loading is indicated in italics. It is clear that the first factor is a 
Table 2. Factor loadings for the indecisiveness scale.

\begin{tabular}{ll}
\hline Item $^{\mathrm{a}}$ & Factor loadings \\
\hline 1 & .692 \\
2 & .776 \\
3 & .631 \\
4 & .499 \\
5 & .742 \\
6 & .683 \\
7 & .691 \\
8 & .725 \\
9 & .636 \\
10 & .678 \\
11 & .663 \\
12 & .582 \\
13 & .636 \\
14 & .573 \\
15 & .594 \\
16 & .501 \\
17 & .439 \\
18 & .492 \\
19 & .485 \\
20 & .347 \\
21 & .539 \\
22 & .460 \\
\hline
\end{tabular}

aitems that are reverse scored are numbered in italics.

career indecision factor, with high loadings on all the 22 items of the career indecision scale. The second factor must be interpreted as an indecisiveness factor, with all of the 22 items of the corresponding scale having high loadings on this second factor.

The second hypothesis concerns the differentiation between indecisiveness and career indecision in how they are correlated with self-esteem. The correlation between the indecisiveness scale and the self-esteem scale was .41 $(n=156, p<.01)$, indicating that low feelings of self-esteem go together with indecisiveness. As expected, the correlation between career indecision and self-esteem is lower, namely $.18(n=156, p<.05)$. The difference between the two correlations is significant, $t(153)=2.70, p<.01$.

\section{Contribution of Indecisiveness to Situational Indecision}

Because a lot of the attention in the literature is paid to the relationship between indecisiveness and career indecision, we decided to investigate this relation more close1y. Next to career indecision, we are also interested in other types of decision making related to daily life. The issue is how much each of these are associated with indecisiveness, and whether this association can also explain their intercorrelations. This is why we tested a model with indecisiveness as a factor that affects all more
Table 3. Factor analysis results for items of the indecisiveness scale (I) and items of the career indecision scale (C): Varimax solution.

\begin{tabular}{|c|c|c|}
\hline Item $^{a}$ & Factor 1 & Factor2 \\
\hline |1 & .082 & .682 \\
\hline 12 & .120 & .771 \\
\hline 13 & .232 & .596 \\
\hline 14 & -.034 & .507 \\
\hline 15 & .202 & .708 \\
\hline 16 & .164 & .654 \\
\hline 17 & .220 & .646 \\
\hline 18 & .098 & .725 \\
\hline 19 & .101 & .622 \\
\hline 110 & .072 & .666 \\
\hline 111 & .119 & .648 \\
\hline 112 & .168 & .551 \\
\hline 113 & .077 & .627 \\
\hline 114 & .067 & .556 \\
\hline 115 & .102 & .576 \\
\hline I16 & .167 & .473 \\
\hline 117 & .160 & .400 \\
\hline 118 & .151 & .452 \\
\hline 119 & .089 & .477 \\
\hline 120 & .009 & .351 \\
\hline 121 & .299 & .487 \\
\hline 122 & .064 & .447 \\
\hline $\mathrm{C} 1$ & .721 & .139 \\
\hline $\mathrm{C} 2$ & .885 & .137 \\
\hline $\mathrm{C} 3$ & .779 & .158 \\
\hline C4 & .536 & .025 \\
\hline$C 5$ & .797 & .148 \\
\hline C6 & .770 & .094 \\
\hline $\mathrm{C7}$ & .785 & .067 \\
\hline C8 & .855 & .161 \\
\hline $\mathrm{Cg}$ & .773 & .079 \\
\hline C10 & .723 & .122 \\
\hline$C 11$ & .792 & .162 \\
\hline $\mathrm{C} 12$ & .605 & .114 \\
\hline $\mathrm{C} 13$ & .602 & .107 \\
\hline C14 & .698 & .185 \\
\hline$C 15$ & .626 & .232 \\
\hline C16 & .531 & .197 \\
\hline $\mathrm{C} 17$ & .753 & .156 \\
\hline C18 & .745 & .176 \\
\hline C19 & .618 & .156 \\
\hline $\mathrm{C} 2 \mathrm{O}$ & .728 & .177 \\
\hline C21 & .740 & .186 \\
\hline $\mathrm{C} 22$ & .662 & .102 \\
\hline
\end{tabular}

aitems that are reverse scored are numbered in italics.

specific types of indecision, career indecision as well as the types of indecision related to daily life, while there is no further association between the different types of indecision. In Table 4 the fit indices are given for the model that was specified in Figure 1 (Model 1, called "basic model" in Table 4).

If we take into account all the three fit indices, it seems that the model doesn't fit the data. To identify the areas of misfit in the model, the residuals in the covariance 
Table 4. Fit indices of the five models for the contribution of indecisiveness to indecision.

\begin{tabular}{llllll}
\hline Model & $\chi^{2}$ & $d f$ & $p$-value $\chi^{2}$ & RMSEA & $p$-value of close fit \\
\hline 1 Basic model & 75.90 & 47 & .005 & .063 & .20 \\
2 No relation with "studying" & 48.00 & 38 & .128 & .041 & .63 \\
3 Without "studying" & 44.01 & 38 & .232 & .032 & .76 \\
4 Equal contribution & 48.51 & 42 & .227 & .032 & .78 \\
5 Differentiation & 354.83 & 44 & .000 & .213 & .00 \\
\hline
\end{tabular}

matrix and the modification indices can be used. According to Byrne (1998) standardized values of the fitted residuals larger than 2.58 have to be considered as large. Two out of the three standardized residuals in the covariance matrix were larger than 2.58, including the item concerning studying one's lessons. The values of those three residuals are: -3.11 for the covariance between the item about studying lessons and the sum I1; 3.17 for the covariance between the item on studying lessons and that on free time; and 3.12 for the covariance between the item on clothes and the item on menu. Furthermore, from the modification indices it is suggested that one add an error covariance (1) between the item concerning studying lessons and the sum of the first eleven items of the indecisiveness scale (sum I1), (2) between the same item and the item concerning free time, and (3) between the item concerning choosing clothes and the item on choosing a menu.

From these results it seems that the item on studying one's lessons is the main cause of misfit. A closer look at the content of this item reveals it to be a somewhat special kind: All the other items on indecision are about choosing between different alternatives, implying that you can choose only one alternative. When studying, however, one has to organize one's time in such a way that in the end one has completed all lessons. It is not a matter of picking out a single lesson, but rather of organizing one's time so that all get finished. Therefore, we tested a model with no links at all between the item on studying and the other variables. The fit indices for this second model (Model 2, given in Table 4) indicate a good fit, providing evidence for the different content of that item. When the item on studying was consequently removed from the model, the fit of this model remains quite good - as it should (see Model 3 in Table 4).

Finally, a model with equal unstandardized paths from indecisiveness to the five specific items of indecision is tested (Model 4). Because the difference in $\chi^{2}$ between Model 4 and Model 3 is not significant, $\chi^{2}(4)=4.5$, we can conclude that the effect of indecisiveness on the decision problems in those five situations is the same. The contribution of indecisiveness to career indecision as well as to indecision in daily life situations is significant $(t(155)=5.10, p<.01$ and $t(155)=6.58, p<.01$ respectively). The effect of indecisiveness on career indecision is higher than on indecision in daily life situations: The standardized loadings of the daily decision problems vary from .22 to .26 , and the standardized loading of career indecision is .40. The difference may stem from career indecision being a latent variable, whereas the other variables are manifest and subject to measurement error.

\section{Further Evidence for the Differentiation Between Career Indecision and Indecisiveness}

To find further evidence for a differentiation between career indecision and indecisiveness, the same model as Model 4 was tested, but without a latent career indecision variable explaining the correlations between the three manifest career indecision variables. In this model (Model 5) indecisiveness has a direct effect on the sum scores of the items about career indecision. The fit of this model is not good (see Model 5 in Table 4), in contrast to the fit of Model 4. These results indicate that the correlations between the manifest career indecision variables cannot be explained only by indecisiveness, but that a second factor is needed, as suggested by the exploratory analysis. Because this second factor is only common to the manifest career indecision variables, it must be interpreted as career indecision.

\section{Cross-Validation}

The ECVI value of Model 4 is .48, whereas that of Model 5 is 2.43. We also compared the ECVI value of Model 4 with that of the saturated model $(\mathrm{ECVI}=.71)$ and the independence model $(\mathrm{ECVI}=4.72)$. Given the lower ECVI value for the hypothesized Model 4, compared with the three other alternative models, Model 4 seems to have the greatest potential for replication in other similar-sized samples.

The partial correlation coefficients between the three career indecision variables, controlled for indecisiveness, are calculated for the two subsamples. The partial correlation coefficients between the sum score of the first 
11 items of the career indecision scale and the last 11 items of this scale are significant in both groups $(.91, p<$ .01 and $.88, p<.01)$. Also the partial correlations of both sum scores with the score on the separate item about how far the students had made progress with the career decision are significant in both groups $(.70, p<.01$ and .74 , $p<.01$, for the correlations between the separate item and the sum score of the first eleven items in each group; $.69, p<.01$ and $.69, p<.01$, for the correlations between the separate item and the sum score of the last eleven items in each group). These results indicate that the correlations in both groups between the career indecision variables cannot be explained only by indecisiveness, and thus corroborate the cross-validation of the differentiation between career indecision and indecisiveness.

\section{Discussion}

The findings from this study provide evidence for the reliability of the indecisiveness scale constructed. The scale has a high internal consistency and the test-retest reliability seems quite high. Furthermore, on the basis of three different criteria, we found evidence for a differentiation between indecisiveness and indecision, specified as career indecision in this study. First, a factor analysis on the items of the indecisiveness scale and a career indecision scale showed evidence for two different factors: an indecisiveness factor, referring to problems students encounter with decision making in general, and a career indecision factor referring to decision problems concerning further studies. Second, it was found that low self-esteem is associated more with indecisiveness than with career indecision. Third, the factor indecisiveness did not suffice to explain the correlations between career indecision variables. The differentiation may have implications for counseling interventions. Persons who are indecisive could require a different type of counseling than persons who are only undecided about a particular subject.

Evidence was found also for an important contribution of indecisiveness to decision making problems in different situations. From the results it seems that the influence of indecisiveness on daily decision problems is the same for a variety of situations. However, we were not able to test the hypothesis of equal influence on the daily decision problems and the career decision problems, because both are measured in a different way. Further research with more extensive but comparable measurements for decision problems of all kinds is needed to investigate the equality of the influence indecisiveness has on different kinds of decisions.

Taken together, the results are in line with the two basic characteristics of indecisiveness described earlier. First, from the one-factor solution of the indecisiveness scale it seems that all the descriptors we mentioned for difficulty in making decisions (a tendency to delay making decisions, a tendency to avoid making decisions, etc.) could indeed be seen as measurements of the same underlying construct. Second, evidence for indecisiveness as referring to all kinds of decisions could be found from the significant effect that indecisiveness in the structural equations model had on decision problems in different situations. Therefore, these results contribute to a clearer conceptualization of indecisiveness.

All the students who participated in this study were 18 years old. According to Salomone (1982), young adults under the age of 25 years should not be labeled as indecisive, and thus the study of indecisiveness should be confined to adults and not to high school students or college students. However, on the basis of the results in this study we must disagree with Salomone: It seems that also for high school students a distinction between indecision and indecisiveness exists. A similar view has been defended by Fuqua and Hartman (1983).

\section{References}

Browne, M.W. (2000). Cross-validation methods. Journal of Mathematical Psychology, 44, 108-132.

Browne, M.W., \& Cudeck, R. (1989). Single sample cross-validation indices for covariance structures. Multivariate Behavioral Research, 24, 445-455.

Browne, M.W., \& Cudeck, R. (1993). Alternative ways of assessing model fit. In K.A. Bollen \& J.S. Long (Eds.), Testing structural equation models (pp.445-455). Newbury Park, CA: Sage.

Byrne, B.M. (1998). Structural equation modeling with LISREL, PRELIS, and SIMPLIS: Basic concepts, applications, and programming. Mahwah, NJ: Erlbaum.

Chartrand, J.M., Robbins, S.B., Morril, W.H., \& Boggs, K. (1990). Development and validation of the Career Factors Inventory. Journal of Counseling Psychology, 37, 491-501.

Cooper, S.E., Fuqua, D.R., \& Hartman, B.W. (1984). The relationship of trait indecisiveness to vocational uncertainty, career indecision, and interpersonal characteristics. Journal of College Student Personnel, 25, 353-356.

Crites, J.O. (1969). Vocational psychology. New York: McGrawHill.

Dosnon, O., Wach, M., Blanchard, S., \& Lallemand, N. (1997). La mesure de l'indécision chez les lycéens: Présentation de trois instruments [The measurement of indecision among high school students: A study of three scales]. L'Orientation Scolaire et Professionnelle, 26, 57-88.

Frost, R.O., \& Shows, D.L. (1993). The nature and measurement of compulsive indecisiveness. Behaviour Research and Therapy, 31, 683-692.

Fuqua, D.R., \& Hartman, B.W. (1983). Differential diagnosis and 
treatment of career indecision. Personnel and Guidance Journal, 62, 27-29.

Gati, I., Krausz, M., \& Osipow, S.H. (1996). A taxonomy of difficulties in career decision making. Journal of Counseling Psychology, 43, 510-526.

Gati, I., Osipow, S.H., Krausz, M., \& Saka, N. (2000). Validity of the Career Decision Making Difficulties Questionnaire: Counselee versus career counselor perceptions. Journal of Vocational Behavior, 56, 99-113.

Harter, S. (1988). Manual for the Self-Perception Profile for Adolescents. Denver, CO: University of Denver.

Jones, L.K. (1989). Measuring a three-dimensional construct of career indecision among college students: A revision of the vocational decision scale - The Career Decision Profile. Journal of Counseling Psychology, 36, 477-486.

Jöreskog, K.G., \& Sörbom, D. (1996). LISREL 8: User's reference guide. Chicago, IL: Scientific Software International.

Jöreskog, K.G., Sörbom, D., du Toit, S., \& du Toit, M. (1999). LISREL ${ }^{\circledR}$ 8: New statistical features. Chicago, IL: Scientific Software International.

Kishor, N. (1981). The effect of self-esteem and locus of control in career decision making of adolescents in Fiji. Journal of Vocational Behavior, 19, 227-232.

Marsh, H.W. (1992). Self Description Questionnaire (SDQ) II: A theoretical an empirical basis for the measurement of multiple dimensions of adolescent self-concept. Test manual and research monograph. Macarthur, New South Wales, Australia: University of Western Sydney, Faculty of Education.

Mertens, W. (1997). Zelf-concept. Theoretische achtergrond en constructie van een meetinstrument voor leerlingen van het $A S O$ en TSO [Self-concept: theory and construction of a mea- surement scale for high school students]. Unpublished Licentiate's Thesis, K.U. Leuven, Leuven, Belgium.

Osipow, S.H. (1999). Assessing career indecision. Journal of Vocational Behavior, 55, 147-154.

Salomone, P.R. (1982). Difficult cases in career counseling: II The indecisive client. Personnel and Guidance Journal, 60, 496-500.

Serling, D.A., \& Betz, N.E. (1990). Development and evaluation of a measure of fear of commitment. Journal of Counseling Psychology, 37, 91-97.

Slaney, R.B. (1988). The assessment of career decision making. In W.B. Walsh \& S.H. Osipow (Eds.), Career decision making (pp. 33-76). Hillsdale, NJ: Erlbaum.

Tyler, L.E. (1969). The work of the counselor (3rd ed.). New York: Appleton-Century-Crofts.

Wanberg, C.R., \& Muchinsky, P.M. (1992). A typology of career decision status: Validity extension of the vocational decision status model. Journal of Counseling Psychology, 39, 71-80.
Veerle Germeijs
Department of Psychology
Catholic University Leuven
Tiensestraat 102
B-3000 Leuven
Belgium
Tel. +32 16 326-126
Fax +32 16 326-144
E-mail veerle.germeijs@psy.kuleuven.ac.be 